\title{
Dynamics of Endogenous Business Cycles and EXchange Rate Volatility*
}

\author{
Volker Böhm and Tomoo Kikuchi
}

May 2002

Discussion Paper No. 486

UNIVERSITY OF BIELEFELD

Department of Economics

P.O. Box 100131

D-33501 Bielefeld

Germany

\begin{abstract}
This paper studies the dynamics of endogenous business cycles and exchange rate volatility in a small open economy. Without market imperfections, domestic price and wage adjustments respond sluggishly to disequilibrium situations on real domestic markets while prices on international capital markets adjust instantaneously. The expectation formation mechanism under uncovered interest rate parity (UIP) induces a channel transmitting potential domestic real fluctuations into exchange rate fluctuations and vice versa. The interaction of the expectations feed back with the adjustment mechanism causes exchange rates to exhibit a higher volatility than other prices. The numerical analysis shows examples which confirm the typical empirically observed high volatility of nominal exchange rates compared with that of real/domestic variables.
\end{abstract}

Keywords: Exchange rate volatility; Business cycles; Uncovered interest parity JEL classification: D5; E3; E44; F31

${ }^{*}$ The research for this paper is part of the project "Endogene stochastische Konjunkturtheorie von Realgüter- und Finanzmärkten" supported by the Deutsche Forschungsgemeinschaft under contract number Bo. 635/9-1,3. We are indebted to M. Meyer for computational assistance and acknowledge discussions with A. Förster who participated in the project at the initial stage. 


\section{Introduction}

International data show that exchange rates exhibit higher volatility than price ratios for countries with floating currencies and open capital markets. This seems to indicate that short run exchange rate volatility would have to be explained under some price rigidities. Moreover, real exchange rates exhibit much less volatility under a fixed exchange rate regime than under a floating regime. This implies that the variability in real exchange rates may not be entirely attributable to real shocks as postulated in real business cycle models, but must also be related to nominal rigidities or disturbances.

Given these empirical observations it seems apparent that theoretical models should attempt to identify those forces (e. g. monetary shocks or others) which interact with sticky prices and which generate the observed volatility in real exchange rates. Some models assuming nominal rigidities within Keynesian open economy models were developed during the 1960s and 1970s (for example, Mundell (1968) and Dornbusch (1976)). Dornbusch focused on the effects of slow price level adjustments in response to movements in money supply. He showed that a permanent monetary expansion causes the nominal exchange rate to depreciate so much that it overshoots its long run value. During the adjustment process commodity prices increase and the exchange rate is appreciated until the Purchasing Power Parity (PPP) holds in the long run equilibrium. A particular feature of this model is the saddle-path-solution. The overshooting result hinges on the assumption that the nominal exchange rate jumps onto the stable manifold of a new system after an unexpected monetary expansion. Furthermore, the model's lack of microfoundations deprives it from any welfare consideration by which to evaluate alternative macroeconomic policies.

Since the late 1970s most of the theoretical models incorporated explicit microfoundations for the private sector's consumption, investment, and production decisions. These models developed implications of dynamic optimization by the private sector while assuming away the observed stickiness of prices.

A new wave of research as documented in the survey by Lane (2001) on new open economy macroeconomics offers a variety of approaches which incorporate price rigidities and market imperfections into a dynamic general equilibrium model with well-specified microfoundations. In contrast to earlier ones with perfect competition, these models with monopolists derive rather than assume incomplete price adjustment. In the literature such as Svensson \& Wijnbergen (1989) and Obstfeld \& Rogoff (1995), firms are assumed to set their prices one period in advance. However, the economy is predicted to adjust to its new long-run equilibrium in a single period in which the law of one price holds and the real exchange rate is constant. This has the counter factual implication that the price level jumps discretely. Contributions such as Chari, Kehoe \& McGrattan (2000), Betts \& Devereux (2000), and Kollmann (2001) permit smooth price level adjustment by allowing firms to adjust their price stochastically. As a consequence, only a fixed fraction of firms adjusts its price each period so that the price level changes only 
gradually over time. The firms can also price discriminate across countries, so there are deviations from the law of one price. It shows that the pricing to market can generate a quantitatively significant increase in exchange rate volatility. Kollmann (2001) and Chari, Kehoe \& McGrattan (2000) examine quantitative dynamic general equilibrium models which produce exchange rate volatility higher than in standard real business cycle models with flexible prices and wages.

These recent contributions attempt to address two of the so called "pricing puzzles" (see Obstfeld \& Rogoff 2001). The first is the PPP puzzle (Rogoff 1996), which highlights the weak connection between exchange rates and national price levels. The second one is the so called exchange-rate-disconnect puzzle (Rogoff 1998), which alludes to the high volatility of exchange rates apparently disconnected from fundamental macroeconomic variables. However, these models cannot explain persistent fluctuations of any variables without exogenous monetary shocks nor can they identify sources for the difference of the volatility of domestic macroeconomic variables versus exchange rates.

This paper differs from these recent developments in the new open economy macroeconomics in choosing a non-Walrasian approach rather than introducing imperfect competition as a source for price stickiness. The presence of non-Walrasian prices in a dynamic context essentially means that prices respond imperfectly to market situations implying sluggish price adjustments. At the same time, trading mechanisms on all markets have to define economic realizations of all relevant variables at all times, i.e. feasible trades at non-Walrasian prices need to be defined. Within the context of perfect competition such trading rules correspond precisely to those developed by the so called fixed price literature, such as Barro \& Grossman (1971), Benassy (1975) and Malinvaud (1977). Here these temporary fixed price situations are integrated into a proper dynamic flex price setting by amending the allocation rules with appropriate price adjustment rules.

The paper presents an extension of the closed economy model of Böhm (1993) and Böhm, Lohmann \& Lorenz (1997) into a small open economy framework in which the expectation formation mechanism in the foreign exchange market is derived explicitly under the uncovered interest rate parity (UIP). This expectation formation works as a channel transmitting domestic business cycles into exchange rate fluctuations and vice versa. The paper offers a general model with explicit dynamics in which endogenous business cycles of a small domestic economy and permanent exchange rate fluctuations interact without exogenous shocks. In section 2 behavioral assumptions of economic agents are derived. Section 3 describes temporary feasible allocations. Section 4 analyzes the dynamics of the model while Section 5 presents simulation results. 


\section{The Structure of the Model}

The model describes a simple dynamic prototype economy with markets for labor, output, and bonds with sluggish price and wage adjustment (as for example in Böhm, Lohmann \& Lorenz (1997)) $)^{1}$ extended to the case of a small open economy (see also Neary 1990). There exists a stationary set of economic agents of the domestic economy consisting of young and old consumers, a single producer, a government, and a central bank.

\subsection{Domestic Consumers}

The private domestic consumption sector consists of overlapping generations of consumers with two period lives. For simplicity, it is assumed that each generation consists of a single consumer only. Each young consumer supplies labor $L_{\max }>0$ inelastically in the first period of his life and receives wage income $w_{t} L_{t}$ for his current employment $L_{t}$ and all profits $\Pi_{t}$ from the producer. After paying a proportional income tax at the rate $0 \leq \operatorname{tax} \leq 1$ his net nominal income is equal to

$$
Y_{t}^{n e t}=(1-\operatorname{tax})\left(w_{t} L_{t}+\Pi_{t}\right)=(1-\operatorname{tax}) y_{t} p_{t} .
$$

Intertemporal preferences of each young consumer are described by a two period utility function, which satisfies the following properties:

Assumption 2.1 The utility function $u: \mathbb{R}_{+}^{2} \longrightarrow \mathbb{R}$ is $C^{2}$, strictly quasi concave, strictly monotonically increasing, and homothetic.

For the subsequent numerical analysis the intertemporal CES utility function of the form

$$
u\left(x_{t}, x_{t+1}\right)= \begin{cases}\frac{1}{\rho}\left(x_{t}^{\rho}+\delta x_{t+1}^{\rho}\right) & \text { if } \rho \neq 0 \\ \ln x_{t}+\delta \ln x_{t+1} & \text { if } \rho=0\end{cases}
$$

will be used, with $\delta>0$ as the time discount factor and $-\infty<\rho<1$ as the parameter of substitution.

Consumption in the second period of each consumer's life is financed through savings in the form of holding retradeable government bonds. Let $r_{t, t+1}^{e}$ denote the consumer's expected nominal rate of return for $t+1$ on bonds at time $t$ and $p_{t, t+1}^{e}$ the expected

\footnotetext{
${ }^{1}$ The model of a closed economy with instantaneous bond market clearing possesses essentially the same temporal and dynamic structure as the one with money alone.
} 
commodity price for $t+1$ at time $t$. Then, the consumption/savings decision of a young consumer is given by the notional commodity demand

$$
x_{t}^{d y}=\arg \max _{x}\left\{u\left(x, \frac{\left(Y_{t}^{n e t}-p_{t} x\right)\left(r_{t, t+1}^{e}\right)}{p_{t, t+1}^{e}}\right)\right\} .
$$

Given the homotheticity of the utility function, notional commodity demand can be written as

$$
x_{t}^{d y}=c\left(R_{t, t+1}^{e}\right) \frac{Y_{t}^{n e t}}{p_{t}},
$$

and notional bond demand is

$$
B_{t}^{d}=\left(1-c\left(R_{t, t+1}^{e}\right)\right) \frac{Y_{t}^{n e t}}{s_{t}}
$$

with $\theta_{t, t+1}^{e}:=\frac{p_{t, t+1}^{e}}{p_{t}}$ as the expected rate of inflation, $R_{t, t+1}^{e}:=\frac{r_{t, t+1}^{e}}{\theta_{t, t+1}^{e}}$ as the expected real rate of return on real savings and $s_{t}$ as the nominal bond price.

For the CES utility function the propensity to consume out of real net income $0<$ $c\left(R_{t, t+1}^{e}\right)<1$ is given by

$$
c\left(R_{t, t+1}^{e}\right)= \begin{cases}\frac{1}{1+\delta^{\frac{1}{1-\rho}}\left(R_{t, t+1}^{e}\right)^{\frac{\rho}{1-\rho}}} & \text { if } \rho \neq 0 \\ \frac{1}{1+\delta} & \text { if } \rho=0\end{cases}
$$

confirming the fact that for $\rho=0$, i.e. for the standard Cobb-Douglas utility function, the propensity to consume is independent of the expected real rate of return.

A typical old consumer in period $t$ with bond holdings $B_{t}$ receives a nominal interest payment $d \geq 0$ per bond and sells his holdings at the nominal price $s_{t}$. He spends his total nominal revenue for consumption, implying a notional consumption demand of

$$
x_{t}^{d o}=\frac{B_{t}}{p_{t}}\left(s_{t}+d\right) \text {. }
$$

\subsection{Domestic Production}

The production sector consists of a single infinitely lived firm, which produces a homogenous commodity $y$ using domestic labor $L$ as the only instantaneous input without possibility for inventory.

Assumption 2.2 The production function $f: \mathbb{R}_{+} \longrightarrow \mathbb{R}_{+}$is $C^{2}$, strictly monotonically increasing, strictly concave, and satisfies the Inada conditions. 
For the numerical analysis the simple production function

$$
y=f(L)=\frac{A}{B} L^{B}
$$

will be used, with $A>0$ as a scaling parameter and $0<B<1$ as the elasticity of production ${ }^{2}$. Maximizing profits in any period $t$ at given price $p_{t}$ and wage $w_{t}$ yields as notional demand for labor and as notional commodity supply

$$
\begin{aligned}
L_{t}^{*}=L^{*}\left(\frac{w_{t}}{p_{t}}\right) & :=\arg \max _{L}\left(p_{t} f(L)-w_{t} L\right), \\
y_{t}^{*}=y^{*}\left(\frac{w_{t}}{p_{t}}\right) & :=f\left(L^{*}\left(\frac{w_{t}}{p_{t}}\right)\right) .
\end{aligned}
$$

For the isoelastic production function one obtains

$$
\begin{aligned}
& L_{t}^{*}=L^{*}\left(\frac{w_{t}}{p_{t}}\right)=\left(\frac{p_{t} A}{w_{t}}\right)^{\frac{1}{1-B}}, \\
& y_{t}^{*}=y^{*}\left(\frac{w_{t}}{p_{t}}\right)=\frac{A}{B}\left(\frac{p_{t} A}{w_{t}}\right)^{\frac{B}{1-B}} .
\end{aligned}
$$

\subsection{The Government and Foreign Demand}

The government has two ways of financing its demand $g>0$. First, it levies a proportional tax at the rate $0 \leq t a x \leq 1$ on the young household's income (wages and profits). Second, the government conducts open market operations to issue new bonds at the rate $\Delta$ in every period. Then, total bond supply in period $t$ is equal to

$$
B_{t}^{s}=B_{t}(1+\Delta), \quad-1<\Delta<\infty .
$$

The government services its bonds by paying a nominal amount $d>0$ per bond each period to the asset holder. $\Delta$ and $d$, as well as $g$ and tax will be treated as exogenous parameters for the discussions of the exchange rate volatility, thus neglecting issues of budget balance for the government.

To complete the description of the real part of the economy, it is assumed that the international real link of the economy is given by an exogenously given nominal demand $E$ in foreign currency units in every period $t$ inducing a nominal demand equal to $E \cdot X_{t}$ in domestic units if $X_{t}$ is the exchange rate.

\footnotetext{
${ }^{2}$ The parameter $B$ chosen for the specific form should not be confused with the nominal stock of bonds denoted $B_{t}$.
} 


\section{$3 \quad$ Temporary Feasible States}

One of the distinctive features of the model is the assumption of an instantaneous adjustment of the bond price to clear the bond market in contrast to sluggish price adjustment in the real markets. Thus, the nominal wage $w$ and the commodity price $p$ are assumed to be given at the beginning of the period and they remain unchanged during the period. As a consequence transactions take place through rationing when prices and wages are not at their Walrasian values. Then, a possible imbalance of demand and supply gives rise to domestic price adjustments in the real markets at the end of the period.

Using the concept of the UIP as an equilibrium device (see Section 4.2 below), the sequential structure of the determination of expectations, of nominal prices, and of nominal exchange rates implies that the nominal exchange rate is also given at the beginning of the period. Thus, all prices except the one for bonds is given and unchanged during one period.

\subsection{Effective Aggregate Demand}

Considering the commodities demanded by all agents, aggregate demand $y$ in any period $t$ must satisfy

$$
y=c\left(R_{t, t+1}^{e}\right)(1-t a x) y+\frac{B_{t} s_{t}}{p_{t}}+\frac{B_{t} d}{p_{t}}+\frac{E X_{t}}{p_{t}}+g .
$$

Solving (3.1) for $y$ one obtains effective aggregate demand

$$
y^{e f f}=\left(\frac{B_{t} d}{p_{t}}+\frac{E X_{t}}{p_{t}}+g\right) \frac{1}{1-c\left(R_{t, t+1}^{e}\right)(1-t a x)}+s \cdot \frac{B_{t}}{p_{t}\left(1-c\left(R_{t, t+1}^{e}\right)(1-t a x)\right)} .
$$

as a function of the bond price $s$ while $\left(B_{t}, X_{t}, p_{t}\right)$ and $R_{t, t+1}^{e}$ are given. If no disequilibrium is allowed in the bond market, the actual bond prices in any period must be determined simultaneously with actual real income. Therefore, equality of notional demand for bonds (2.4) by young consumers with bond supply (2.10) implies the bond market clearing condition

$$
p_{t} y(1-\operatorname{tax})-p_{t} y(1-\operatorname{tax}) c\left(R_{t, t+1}^{e}\right)=s B_{t}(1+\Delta) .
$$

As a consequence, the solution $\left(s^{d}, y^{d}\right)$ of (3.2) and (3.3) simultaneously determines effective aggregate commodity demand $y^{d}$ and the demand consistent equilibrium bond price $s^{d}$ as

$$
y^{d}=\frac{1+\Delta}{t a x+\Delta\left[1-c\left(R_{t, t+1}^{e}\right)(1-t a x)\right]}\left(\frac{B_{t} d}{p_{t}}+\frac{E X_{t}}{p_{t}}+g\right),
$$




$$
s^{d}=\frac{\left(1-c\left(R_{t, t+1}^{e}\right)\right)(1-\operatorname{tax})}{\frac{B_{t}}{p_{t}}\left(\operatorname{tax}+\Delta\left[1-c\left(R_{t, t+1}^{e}\right)(1-\operatorname{tax})\right]\right)}\left(\frac{B_{t} d}{p_{t}}+\frac{E X_{t}}{p_{t}}+g\right) .
$$

Notice, that the two solutions are homogeneous of degree zero in $\left(B_{t}, X_{t}, p_{t}\right)$. Therefore, let $b_{t}:=B_{t} / p_{t}$ denote real bonds and $x_{t}:=X_{t} / p_{t}$ denote the real exchange rate. Then, for given parameters $(g, t a x, d, \Delta)$ equations (3.4) and (3.7) define effective aggregate demand

$$
y^{d}=\mathcal{D}\left(b, x, R^{e}\right):=\frac{(1+\Delta)(b d+x E+g)}{\operatorname{tax}+\Delta\left(1-c\left(R^{e}\right)(1-\operatorname{tax})\right)}
$$

and the demand consistent bond price

$$
s^{d}=\mathcal{S}^{d}\left(b, x, R^{e}\right):=\frac{\left(1-c\left(R^{e}\right)\right)(1-\operatorname{tax})(b d+x E+g)}{b\left(\operatorname{tax} \Delta\left(1-c\left(R^{e}\right)\right)(1-\operatorname{tax})\right)}
$$

as functions of real bonds, the real exchange rate, and of the expected rate of return for any period $t$. The time subscript has been eliminated since all arguments refer to the same (current) time period.

\subsection{Temporary Feasible Allocations}

Let $v:=\left(b, \alpha, x, R^{e}\right)$ denote the temporary state vector given at the beginning of an arbitrary period where $\alpha:=w / p$ denotes the real wage. To obtain feasible transactions in the commodity market and in the labor market the minimum rule is employed for the rationing mechanism. Therefore, actual output $y$ is the minimum of aggregate commodity demand $y^{d}$, notional supply of goods $y^{*}$, and of capacity output $y_{\max }=$ $f\left(L_{\max }\right)$. Notional supply is a function of the real wage alone. Therefore, feasible output $y$, employment $L$, and the equilibrium bond price $s$ are functions of $v$ given by ,

$$
\begin{aligned}
& y=\mathcal{Y}(v):=\min \left\{\mathcal{D}(v), y^{*}(\alpha), y_{\max }\right\} \\
& L=\mathcal{L}(v):=f^{-1}(\mathcal{Y}(v)) \\
& s=\mathcal{S}(v):=\frac{\left(1-c\left(R^{e}\right)\right)(1-\operatorname{tax})}{b(1+\Delta)} \mathcal{Y}(v),
\end{aligned}
$$

where the last equation uses the bond market clearing condition (3.3) plus the assumption that young consumers are never rationed in the commodity market. Thus, one obtains the following lemma.

\section{Lemma 3.1}

Given the parameters $\left(g, t a x, d, \Delta, L_{\max }, E\right)$, any temporary state vector $v \gg 0$ induces a unique positive temporary feasible allocation $(y, L)$ given by equations (3.8) and (3.9). Equation (3.10) determines a positive market clearing bond price if $\Delta>-1$. 


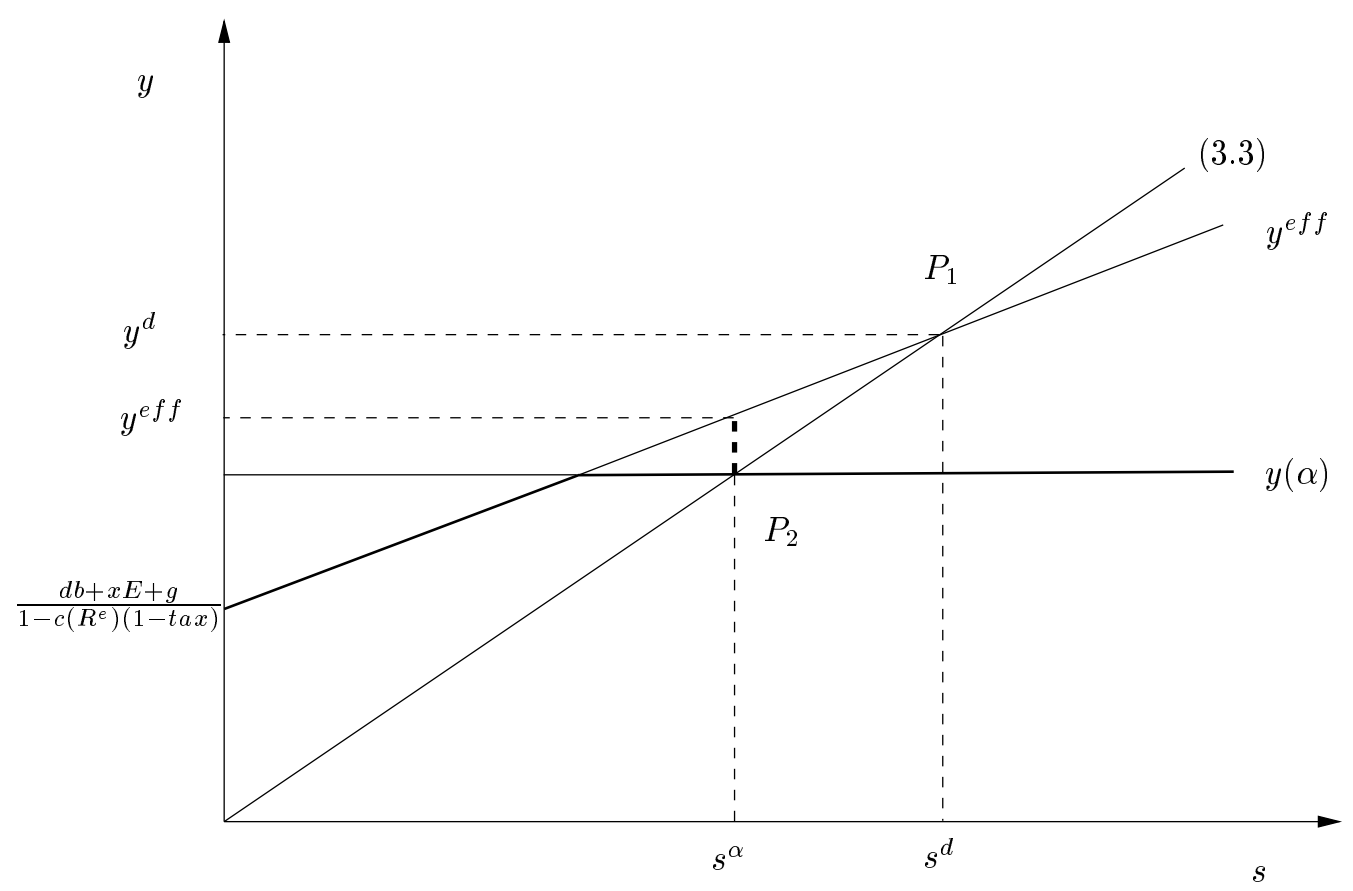

Figure 3.1: Bond market equilibrium

Figure 3.1 provides a geometric description of the determination of actual income $y$ and the actual bond price $s$.

If feasible output is $y=y^{d}<y(\alpha):=\min \left\{f\left(L_{\max }\right), y^{*}(\alpha)\right\}$, i.e. if there is no excess demand in the commodity market but unemployment, $y$ is given by point $P_{1}$ in Figure 3.1. This state, in which the supply side of each market is rationed is referred to as the Keynesian unemployment regime $\mathbf{K}$.

If $y=y(\alpha)<y^{d}$, there is excess demand in the commodity market, so that, in general, the nature of the rationing scheme would affect the dynamics of the equilibrium bond price. The assumption that young consumers are not demand rationed eliminates that influence. Therefore, the feasible pair $\left(s^{\alpha}, y(\alpha)\right)$ is given by the intersection between $y(\alpha)$ and equation (3.3), point $P_{2}$ in Figure 3.1.

The point $P_{2}$ characterizes two situations, depending on the level of actual employment $\left(L \leq L_{\max }\right)$ : one with unemployment, the other one with excess demand on the labor market. If $L<L_{\max }$ there is demand rationing on the commodity market and simultaneously the young household is rationed on the labor market. Such a situation is referred to as the classical unemployment regime $\mathbf{C}$, in which notional commodity supply is realized. The other situation is called the repressed inflation regime $\mathbf{I}$, in which capacity output is realized. In this case there is no unemployment. However, firms are rationed on the labor market and there is demand rationing on the commodity market. The size of rationing, the gap between $y^{e f f}$ and $y(\alpha)$ for a given equilibrium bond price is shown by the vertical bold dashed line. The feasible allocation moves between $P_{1}$ and the origin. 


\section{Dynamics and Expectations Formation}

Existence and uniqueness of temporary feasible states provide the basis for analyzing a well defined forward recursive structure of the dynamic development of the economy over time. This requires the description of the dynamical evolution of all state variables of a dynamical system in the mathematical sense. The dynamic equations for the real wage and real bonds are derived first. The dynamics of the exchange rate and the expectations processes are discussed afterwards.

\subsection{Adjustment of Prices, Wages, and Bond Holdings}

Any temporary state vector $v=\left(b, \alpha, x, R^{e}\right)$ uniquely determines the state of the economy for given parameters which in most cases is not the Walrasian equilibrium. This means that quantity constraints occur on the labor and/or on the commodity market which lead to price and/or wage adjustment at the end of the period according to the size of rationing. The adjustments are assumed to follow the so called "law of supply and demand". This means, if supply exceeds demand in a market, its price goes down and vice versa. A possible formulation of this principle implies the definition of disequilibrium signals for the labor market $s^{l} \in[-1,1]$ and for the goods market $s^{c} \in[-1,1]$. They indicate the sign and the size of rationing. Their dependence on the temporary state vector $v=\left(b, \alpha, x, R^{e}\right)$ is described by two functions $\sigma^{l}$ and $\sigma^{c}$ :

$$
\begin{array}{rll}
\sigma^{c}: & \mathbb{R}_{++}^{4} \rightarrow[-1,+1]: & s^{c}=\sigma^{c}(v) \\
\sigma^{l}: & \mathbb{R}_{++}^{4} \rightarrow[-1,+1]: & s^{l}=\sigma^{l}(v) .
\end{array}
$$

The signs of the signals correspond to the signs of the respective excess demand functions. Apart from the situation when $y^{d}=y^{*}<y^{\max }$ the signal functions $\sigma^{l}(v)$ and $\sigma^{c}(v)$ are assumed to be continuous ${ }^{3}$. Then, on the basis of any pair of disequilibrium signals $\left(s_{t}^{c}, s_{t}^{l}\right)$ in period $t$, a price adjustment function $P$ and a wage adjustment function $W$ are defined to obtain

$$
\begin{array}{ll}
P:[-1,1] \longrightarrow(-1,+\infty), & \frac{p_{t+1}}{p_{t}}=1+P\left(s_{t}^{c}\right), \\
W:[-1,1] \longrightarrow(-1,+\infty), & \frac{p_{t+1}}{p_{t}}=1+P\left(s_{t}^{c}\right) .
\end{array}
$$

$P$ and $W$ are continuous, strictly monotonically increasing, and satisfy $W(0)=P(0)=$ 0 . Together with the signaling function they induce two mappings for price $\mathcal{P}:=P \circ \sigma^{c}$ and wage $\mathcal{W}:=W \circ \sigma^{l}$ adjustment

$$
p_{t+1}=p_{t}\left[1+P\left(\sigma^{c}\left(v_{t}\right)\right)\right]=p_{t}\left(1+\mathcal{P}\left(v_{t}\right)\right),
$$

\footnotetext{
${ }^{3}$ Note that if $y^{d}=y^{*}<y^{\max }$ there is no price adjustment in both markets even though the commodity market is not in equilibrium. To avoid this we assume that $\sigma^{l}(v)>\sigma^{c}(v)$ in this particular case.
} 


$$
w_{t+1}=w_{t}\left[1+W\left(\sigma^{l}\left(v_{t}\right)\right)\right]=w_{t}\left(1+\mathcal{W}\left(v_{t}\right)\right) .
$$

The following special functional form of price and wage adjustment will be used in the numerical simulations below.

$$
\mathcal{P}(v)= \begin{cases}\gamma \frac{y^{e f f}-y}{y^{e f f}} & \text { if } y^{d}>y \\ \kappa \frac{y-y^{*}}{y^{*}} & \text { otherwise }\end{cases}
$$

with $0<\gamma<1$ and $0<\kappa<1$ as adjustment speeds. If $\mathbf{K}$ holds, excess supply in the commodity market gives a downward pressure for the price. If $y^{d}=y^{*}=y$, i.e. if $\mathbf{C} \cap \mathbf{K}$ holds, the commodity market is in equilibrium and there is no price adjustment. In all other cases, i.e. if $\mathbf{I}, \mathbf{C}$ or $\mathbf{C} \cap \mathbf{I}$ holds, there is excess demand in the commodity market and an upward pressure for the price. Applying the same principle to the labor market one obtains

$$
\mathcal{W}(v)= \begin{cases}\lambda \frac{L-L_{\max }}{L_{\max }} & \text { if } L_{\max }>L \\ \mu \frac{L^{*}-L}{L^{*}} & \text { otherwise }\end{cases}
$$

with $0<\lambda<1$ and $0<\mu<1$ as adjustment speeds. If $\mathbf{I}$ holds, excess demand in the labor market gives an upward pressure for the wage rate. If $L_{\max }=L^{*}=L$, i.e. if $\mathbf{C} \cap \mathbf{I}$ holds, the labor market is in equilibrium and there is no wage adjustment. In all other cases $(\mathbf{C}, \mathbf{K}$ or $\mathbf{C} \cap \mathbf{K})$ there is excess supply in the labor market and a downward pressure for the price.

Together the two adjustment functions imply the dynamic equation for the real wage

$$
\alpha_{t+1}=\alpha_{t} \frac{1+\mathcal{W}\left(v_{t}\right)}{1+\mathcal{P}\left(v_{t}\right)}
$$

The assumptions concerning bond market equilibrium imply that total final bond holdings by young consumers in period $t$ are equal to $B_{t+1}=B_{t}(1+\Delta)$. Therefore, the dynamics of real bonds are given by

$$
b_{t+1}=b_{t} \frac{1+\Delta}{1+\mathcal{P}\left(v_{t}\right)}
$$

\subsection{Uncovered Interest Parity and Expectations Formation}

One of the interpretations of the uncovered interest parity (UIP) is that of a condition of expected no arbitrage to hold in perfect international capital markets. When applying the UIP to a dynamic model it is important to take proper account of the sequential structure of the available information and of expectations formation. Let $r^{f}$ denote the 
nominal rate of return for holding foreign assets. Under the UIP expected returns on domestic and foreign capital markets are assumed to be the same. When purchasing foreign bonds in $t$, the amount of domestic investment has to be converted at the spot exchange rate $X_{t}$ into the foreign currency. One period later the accumulated principle plus interest of foreign currency has to be reconverted into domestic currency at the future spot exchange rate $X_{t+1}$. Thus, under expected no arbitrage, the expected returns denominated in either currency have to be the same, implying the following form of the UIP

$$
r_{t, t+1}^{e}=r^{f} \frac{X_{t, t+1}^{e}}{X_{t}}
$$

Rearranging terms one obtains an equation determining the nominal exchange rate

$$
X_{t}=X_{t, t+1}^{e} \frac{r^{f}}{r_{t, t+1}^{e}}
$$

as a function of expectations formed prior to the realization of the current exchange rate. Thus, the sequential structure of the expectations formation implicit in the condition of the UIP reveals that the dynamic equation determining the actual exchange rate is a function of expectations alone independent of the previous actual exchange rate. Moreover, when forming expectations for $t+1$ agents can use observable information only up to $t-1$, implying a so called "expectational lead" for the functional relationship 4 . Figure 4.1 shows the timing of expectations and of exchange rate determination under

\begin{tabular}{|c|c|c|}
\hline$t-1$ & $t$ & $t+1$ \\
\hline$X_{t-1}$ & $X_{t}$ & $X_{t+1}$ \\
\hline$X_{t-1, t}^{e}, r_{t-1}^{e}$ & $X_{t, t+1}^{e}, r_{t}^{e}$ & $X_{t+1, t+2}^{e}, r_{t+1}^{e}$ \\
\hline
\end{tabular}
UIP.

Figure 4.1: Timing of expectations and exchange rates under UIP

In most models imposing the UIP, it is assumed that agents have perfect foresight with respect to the exchange rate, a property which can be guaranteed here by deriving an explicit forecasting scheme. Considering the timing of expectations formation, the perfect foresight property implies that the difference between the forecast $X_{t-1, t}^{e}$ made in $t-1$ and the actual value $X_{t}$, must be equal to zero, i. e. one must have

$$
X_{t, t+1}^{e} \frac{r^{f}}{r_{t, t+1}^{e}}-X_{t-1, t}^{e}=0 .
$$

\footnotetext{
${ }^{4}$ Such expectational leads with independence occur in a natural way in many intertemporal equilibrium models when the sequential structure of the expectations formation process is made explicit.
} 
Solving for $X_{t, t+1}^{e}$ yields the unique explicit functional form of the perfect predictor $\psi_{*}$ for the exchange rate:

$$
X_{t, t+1}^{e}=\psi_{*}\left(X_{t-1, t}^{e}, r_{t, t+1}^{e}\right):=\frac{r_{t, t+1}^{e}}{r^{f}} X_{t-1, t}^{e}
$$

Therefore, the assumption of perfect foresight together with UIP requires that the prediction of the exchange rate is a function of previous predictions and not of previous exchange rates. In other words, the prediction of the exchange rate today guarantees that the prediction of yesterday will be correct $^{5}$.

The expectations formation for the domestic rate of return $r^{e}$ as well as for the inflation rate $\theta^{e}$ could take a variety of different forms. As for the exchange rate, one could ask whether it is possible to derive a perfect predictor as well. In principle, this seems to be possible using the techniques from Böhm \& Wenzelburger (1999). However, due to the non linearities of the equations involved an explicit solution for the perfect predictor cannot be calculated. Therefore, an adaptive (but not perfect) expectations formation rule will be used for the domestic rate of return and for the inflation rate. Observe, however, that the resulting dynamics will in general depend on the choice of the adaptive scheme.

Let $s_{t-1}$ denote the purchase price for bonds, $s_{t}$ the selling price, and $d$ the dividend payment. Then, the rate of return on domestic bonds effective in period $t$ is given by

$$
r_{t}=\frac{d+s_{t}}{s_{t-1}}
$$

The expectation formation of the rate of return is assumed to follow the simple adaptive rule $r_{t, t+1}^{e}=r_{t-1}$, inducing a predictor $\psi^{r}$ of the form

$$
r_{t, t+1}^{e}=\psi^{r}\left(s_{t-1}, s_{t-2}\right):=\frac{d+s_{t-1}}{s_{t-2}} .
$$

Notice two special features present in any adaptive scheme using past data. First, resulting from the sequential structure, the prediction $r_{t, t+1}^{e}$ has to be made prior to the realization of the bond price $s_{t}$, implying that the value for $r_{t}$ is not available as information. Second, the definition of $r_{t-1}$ implies an additional delay of order two with respect to bond prices, thus increasing the dimensionality of the dynamical system.

Similarly, assume that the adaptive scheme for prices defines the expected inflation rate $\theta_{t, t+1}^{e}:=p_{t, t+1}^{e} / p_{t}$ for period $t+1$ as a function of the last $\tau \geq 1$ inflation rates:

$$
\theta_{t, t+1}^{e}=\Psi\left(\theta_{t-1}, \ldots, \theta_{t-\tau}\right) \quad \text { with } \quad \theta_{t-k}=\frac{p_{t-k+1}}{p_{t-k}}, \quad k=1, \ldots, \tau \geq 1
$$

\footnotetext{
${ }^{5}$ This special property of the perfect predictor follows directly from the two structural properties of the exchange rate mapping (4.10), the presence of an expectational lead and of the independence of the previous actual exchange rate (for a general treatment see Böhm \& Wenzelburger 1997).
} 
The function $\Psi: \mathbb{R}_{+}^{\tau} \rightarrow \mathbb{R}_{+}$is assumed to be continuous satisfying the following property:

$$
\Psi(\theta, \theta, \ldots, \theta)=\theta \quad \forall \theta>0
$$

The class of such functions includes most of the commonly used adaptive prediction mechanisms with finite memory.

\subsection{Dynamical System}

It is apparent that the evolution of the economic model will be governed by an interaction of the adjustment equations with the expectations formation rules inducing two strong expectations feed backs. These are decisive in the stability and in the long run behavior of the economy. Combining the dynamic equations for the domestic economy with the appropriate mappings for the expectations processes $\psi_{*}, \psi^{r}$, and $\Psi$ for the expected inflation rate, the expected interest rate, and for the exchange rate

$$
\begin{aligned}
X_{t, t+1}^{e} & =\psi_{*}\left(X_{t-1, t}^{e}, r_{t, t+1}^{e}\right), \\
\theta_{t, t+1}^{e} & =\Psi\left(\theta_{t-1}, \ldots, \theta_{t-\tau}\right), \\
r_{t, t+1}^{e} & =\psi^{r}\left(s_{t-1}, s_{t-2}\right), \\
R_{t, t+1}^{e} & :=\frac{r_{t, t+1}^{e}}{\theta_{t, t+1}^{e}}
\end{aligned}
$$

one obtains as the vector of state variables

$$
\underline{v_{t}}=\left(b_{t}, \alpha_{t}, x_{t-1, t}^{e}, s_{t-1}, s_{t-2}, \theta_{t-1}, \ldots, \theta_{t-\tau}\right)
$$

where $x_{t-1, t}^{e}=X_{t-1, t}^{e} / p_{t}$. Then, the dynamical system is defined by the following mapping:

$$
\begin{aligned}
b_{t+1}=\mathcal{B}\left(\underline{v}_{t}\right):=\frac{b_{t}(1+\Delta)}{1+\mathcal{P}\left(\underline{v}_{t}\right)} \\
\alpha_{t+1}=\mathcal{A}\left(\underline{v}_{t}\right):=\alpha_{t} \cdot \frac{1+\mathcal{W}\left(\underline{v}_{t}\right)}{1+\mathcal{P}\left(\underline{v}_{t}\right)} \\
\theta_{t}=\Upsilon\left(\underline{v}_{t}\right):=1+\mathcal{P}\left(\underline{v}_{t}\right) \\
s_{t}=\mathcal{S}\left(\underline{v}_{t}\right):=\frac{\left[1-c\left(R_{t, t+1}^{e}\right)\right](1-\operatorname{tax}) \mathcal{Y}\left(\underline{v}_{t}\right)}{(1+\Delta) b_{t}} \\
x_{t, t+1}^{e}=\Phi\left(\underline{v}_{t}\right):=\frac{x_{t-1, t}^{e}}{1+\mathcal{P}\left(\underline{v}_{t}\right)} \frac{r_{t, t+1}^{e}}{r^{f}}
\end{aligned}
$$


The vector of past bond prices and past inflation rates $\left(s_{t-1}, s_{t-2}, \theta_{t-1}, \ldots, \theta_{t-\tau}\right)$ is just shifted by one time step. Therefore the dynamic behavior of the economy is described by a sequence $\left\{b_{t}, \alpha_{t}, x_{t-1, t}^{e}, s_{t-1}, s_{t-2}, \theta_{t-1}, \ldots, \theta_{t-\tau}\right\}_{t_{0}}^{T}$ implying a state space of the dynamical system equal to $\mathbb{R}_{+}^{5+\tau}$. The system exhibits a highly nonlinear structure. This arises not only from the many non linear functional relationships but also from the regime switching which occurs induced by the temporary state variables. In the case of a Cobb-Douglas utility function, which implies a constant marginal propensity to consume with no domestic expectations feed back, the dynamical system has dimension five with a one period delay in the bond price. Figure (4.2) illustrates the sequential structure when there is no expectations feed back on domestic consumption, where the solid arrows identify the individual mappings of (4.17).

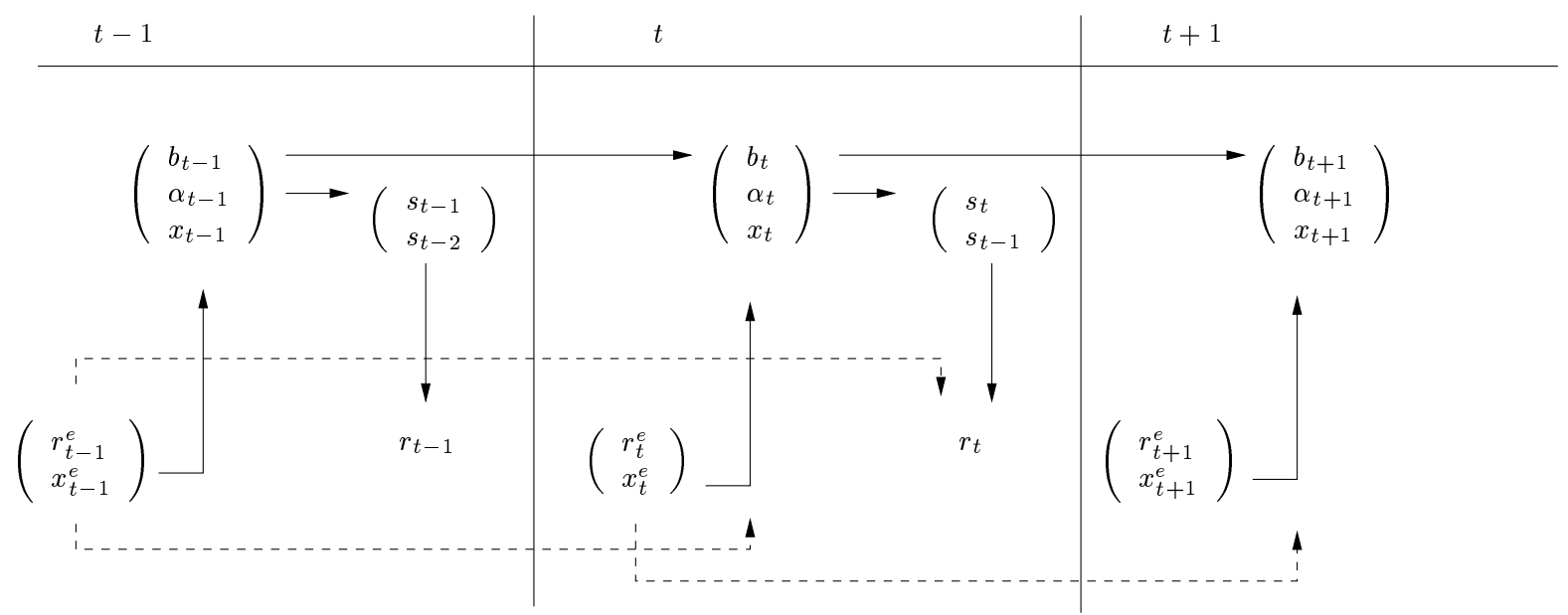

Figure 4.2: Sequential structure of prices, exchange rates, and expectations under UIP

Figure 4.3 illustrates the time one map of the dynamical system (4.17). The vertical arrows indicate that the expectation of inflation rates, of interest rates, and of exchange rates at time $t$ for period $t+1$ are formed on the basis of past realizations of the economic variables. On the other hand the allocation and the corresponding rationing situation at $t$ depend on these forecasts. It is obvious that the system possesses a lag-structure: the bond price, the inflation rate, and the expectation of the exchange rate influence the actual market process at least over two periods. 


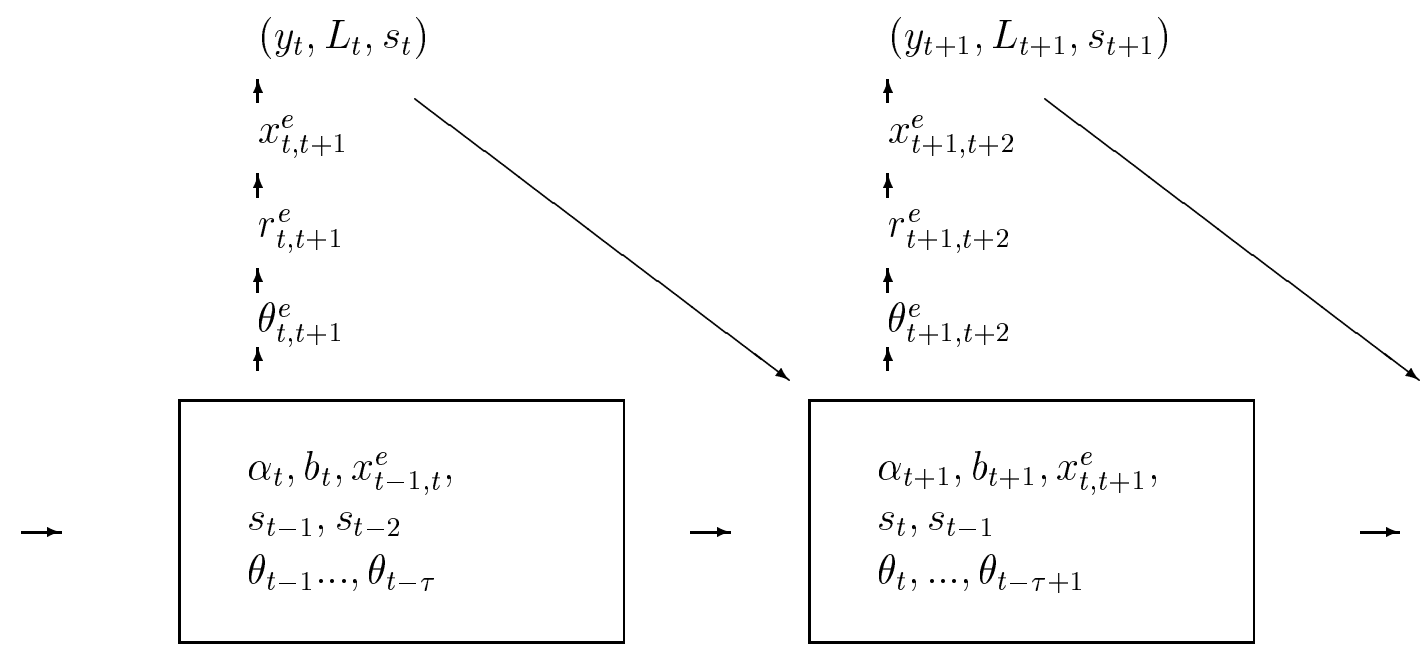

Figure 4.3: Structure of time one map

\subsection{Stationary States}

Due to the high dimensionality of the dynamical system (4.17), it is obvious that a general analytic description of the characteristics of its stationary states and their stability properties may be beyond reach. Fortunately, many features for the associated model of a closed economy are well understood (see Böhm, Lohmann \& Lorenz (1997) and Kaas (1995)) and some of them carry over directly to the small open economy case, as those stated in the next lemma.

\section{Lemma 4.1}

Given a feasible list of the parameters $\left(g, \operatorname{tax}, \Delta, r^{f}, L_{\max }, E\right)$ of the system (4.17) and assume that

$$
\frac{1+\Delta}{\operatorname{tax}+\Delta\left[1-c\left(R_{t, t+1}^{e}\right)(1-\operatorname{tax})\right]} g<y_{\max } .
$$

There exists a unique stationary state $(b, \alpha, \theta, s, x)>>0$ with perfect foresight such that

1. $0<\theta<1$ if and only if $\Delta<0$, and the state is of the Keynesian unemployment type $\mathbf{K}$,

2. $\theta=1$ if and only if $\Delta=0$, and the state is of the Walrasian type $\mathbf{W}$,

3. $\theta>1$ if and only if $\Delta>0$ and the state is of the repressed inflation type $\mathbf{I}$. 
This result states that the sign of the policy parameter $\Delta$ determines uniquely the type of an interior long run disequilibrium state independent of the specific functional forms and the mechanisms. This is one of the fundamental insights into the structural features of this class of models. As a consequence, this implies that the local stability properties of any stationary state are regime specific ${ }^{6}$. Moreover, for $\Delta \neq 0$ local stability properties as well as bifurcation properties can be derived using standard techniques.

\section{$5 \quad$ Numerical Analysis}

For the stability analysis it is necessary to use specific functional forms for the intertemporal preferences and for the technology as the ones introduced above. Those have proved to generate tractable numerical results for the closed economy model. Therefore, for the remainder of this paper, consider the economy with intertemporal preferences of the CES type (2.1) with $\rho=0$, isoelastic production (2.7), and with linear price and wage adjustments of the form (4.5) and (4.6). The assumption on preferences eliminates the expectations feed back on domestic consumption implying a constant propensity to consume and no role for the inflation predictor $\Psi$. Therefore, the dimension of the dynamical system is five with the state variables $\left(b, \alpha, s_{-2}, s_{-1}, x^{e}\right)$. Even for this special case a full derivation of the eigenvalues for $\Delta \neq 0$ has not yet been obtained. The following partial results and numerical simulations are designed to demonstrate that

1. for some large sets of parameters period doubling bifurcations occur while for other ranges of parameters fold bifurcations (saddle point properties) seem to be the cause of the non periodic fluctuations,

2. there is wide (robust) confirmation of excess volatility of exchange rates compared to domestic real variables in the non periodic as well as in the periodic case,

3. there is a loss of stability of the domestic economy after introducing foreign demand.

\subsection{Bifurcation Analysis}

The results from the numerical analysis support the intuition that for some large sets of parameters the type of bifurcations which occur are of the same nature as the ones known from the closed economy analogues (see Kaas 1995). There the loss of local stability and the bifurcations occur essentially when the sum of the elasticity of labor in production and of the adjustment speeds of prices and wages are higher than some critical value implying a negative stability trade off between them. The same phenomenon is found

\footnotetext{
${ }^{6}$ Note that there is no unique stationary state of the classical type $\mathbf{C}$ since the real wage $\alpha$ always decreases in that regime.
} 
here as well in the numerical simulations. However, for other ranges of the parameters this does not hold. In these cases, the period doubling scenarios disappear and non periodic behavior predominates with unstable stationary states.

\section{Proposition 5.1}

There exists a large critical set of parameter values $\left(g, \operatorname{tax}, \Delta, r^{f}, L_{\max }, E\right)$ for which the stationary states of the system (4.17) undergo a period doubling bifurcation for $\Delta \neq$ 0. As a consequence, there exists a large open set of parameter values such that the stationary states are locally unstable and the system displays finite as well as complex cycles.

Table 1 provides a complete list of all parameters used. The two cases analyzed here differ only by their choice in the adjustment speeds in domestic markets.

\begin{tabular}{|c|c|c|c|}
\hline parameter & description/origin & complex & finite \\
\hline$\gamma$ & adjustment speed $p_{t}$ & $\mathbf{0 . 5}$ & $\mathbf{0 . 4}$ \\
$\kappa$ & adjustment speed $p_{t}$ & $\mathbf{0 . 5}$ & $\mathbf{0 . 4}$ \\
$\lambda$ & adjustment speed $w_{t}$ & $\mathbf{0 . 5}$ & $\mathbf{0 . 4}$ \\
$\mu$ & adjustment speed $w_{t}$ & $\mathbf{0 . 5}$ & $\mathbf{0 . 4}$ \\
\hline$g$ & government demand & 0.4 & 0.4 \\
$t a x$ & income tax rate & 0.35 & 0.35 \\
\hline$\Delta$ & new issues of bonds & -0.05 & -0.05 \\
$d$ & nominal interest & 0.01 & 0.01 \\
\hline$A$ & scaling parameter & 1 & 1 \\
$B$ & elasticity of production & 0.76 & 0.76 \\
\hline$L_{\max }$ & constant labor supply & 1 & 1 \\
\hline$\delta$ & time discount factor & 1 & 1 \\
$\rho$ & parameter of substitution & 0 & 0 \\
\hline$\tau$ & expectational lag & 10 & 10 \\
\hline$r^{f}$ & foreign rate of return & 0.01 & 0.01 \\
$E$ & foreign demand for goods & 0.01 & 0.01 \\
\hline$b_{0}$ & initial real bond & 0.6 & 0.6 \\
$\alpha_{0}$ & initial real wage & 0.6 & 0.6 \\
$s_{0}$ & initial bond price & 0.75 & 0.75 \\
$x_{0}^{e}$ & initial real expected exchange rate & 0.5 & 0.5 \\
\hline
\end{tabular}

Table 1: Standard parameter set

The first two diagrams characterize typical scenarios which occur. Figure 5.1 shows a cascade of period doubling bifurcations over the production elasticity $B$ for constant adjustment speeds equal to 0.5. Figure 5.2 provides evidence of the robustness of the period doubling scenario in the form of a so called cyclogram over $B$ and all adjustment speeds $\gamma=\kappa=\lambda=\mu$ simultaneously. A cyclogram is a qualitative multidimensional bifurcation diagram. For each pair of parameters $(B, \gamma=\kappa=\lambda=\mu)$ the respective color assignment indicates the order of the cycle of the limiting behavior of the system. According to the codes given in Figur 5.3 the color "yellow" indicates non periodic 
limiting behavior. One easily verifies the features of the bifurcation diagram Figure 5.1 by traversing horizontally at the value $\gamma=\kappa=\lambda=\mu=0.5$ in Figure 5.2 as well as the stability trade off between the elasticity $B$ and the adjustment speeds $\gamma=\kappa=\lambda=\mu$.

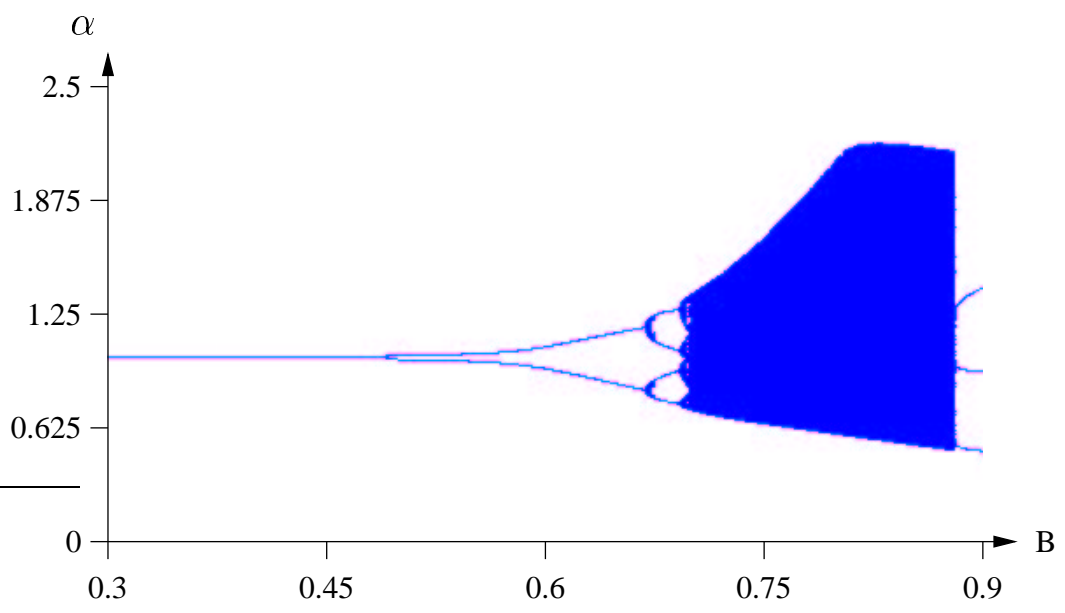

Figure 5.1: $\gamma=\kappa=\lambda=\mu=0.5, E=0.01, \Delta=-0.05$

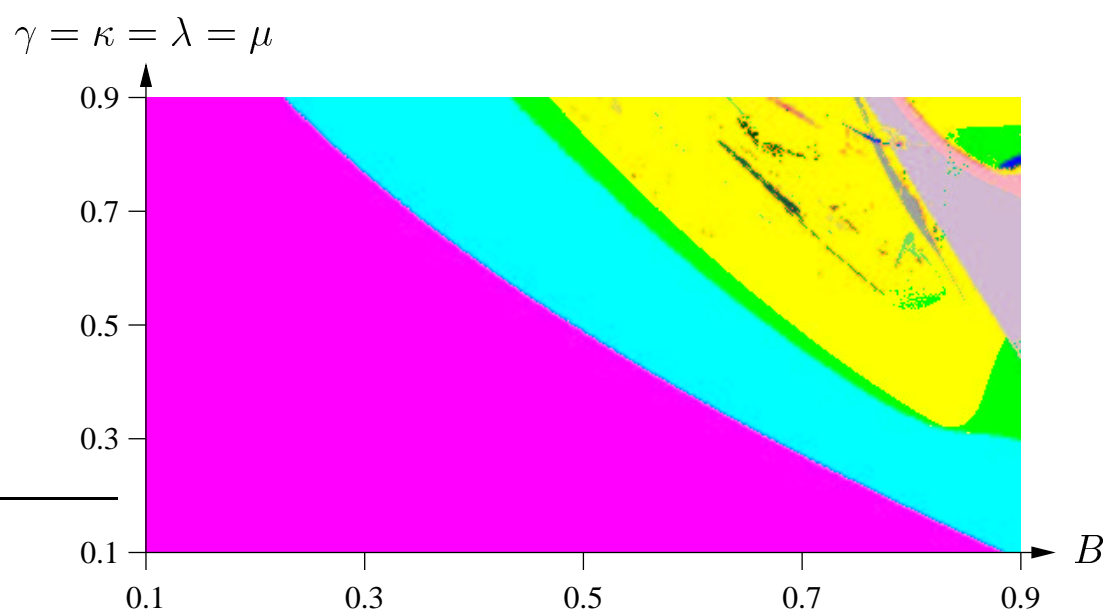

Figure 5.2: $B \in[0.1,0.9], \gamma=\kappa=\lambda=\mu \in[0.1,0.9], \mathrm{E}=0.01, \Delta=-0.05$

\begin{tabular}{|c|c|c|c|c|c|c|c|}
\hline Order 1 & Order 2 & Order 3 & Order 4 & Order 5 & Order 6 & Order 7 & Order 8 \\
\hline Order 9 & Order 10 & Order 11 & Order 12 & Order 13 & Order 14 & Order 15 & Order 16 \\
\hline Order 17 & Order 18 & Order 19 & Order 20 & Order 21 & Order 22 & Order 23 & Order 24 \\
\hline Order 25 & Order 26 & Order 27 & Order 28 & Order 29 & Order 30 & oor & Chaotic \\
\hline
\end{tabular}

Figure 5.3: Color Code 


\subsection{Exchange Rate Volatility}

For investigations of the exchange rate volatility we use our standard parameter sets, which only differ in the adjustment speeds. Adjustment speeds are set to 0.5 to analyze the non periodic cycles and 0.4 to analyze the periodic cycles.

\section{Non Periodic Cycles}

Figures 5.4 and 5.5 show a projection of the attractor (plotting the last 90 per cent of $10^{6}$ iterations) for the domestic economy displaying almost equal variation of inflation and of the real wage, but a clear negative correlation.

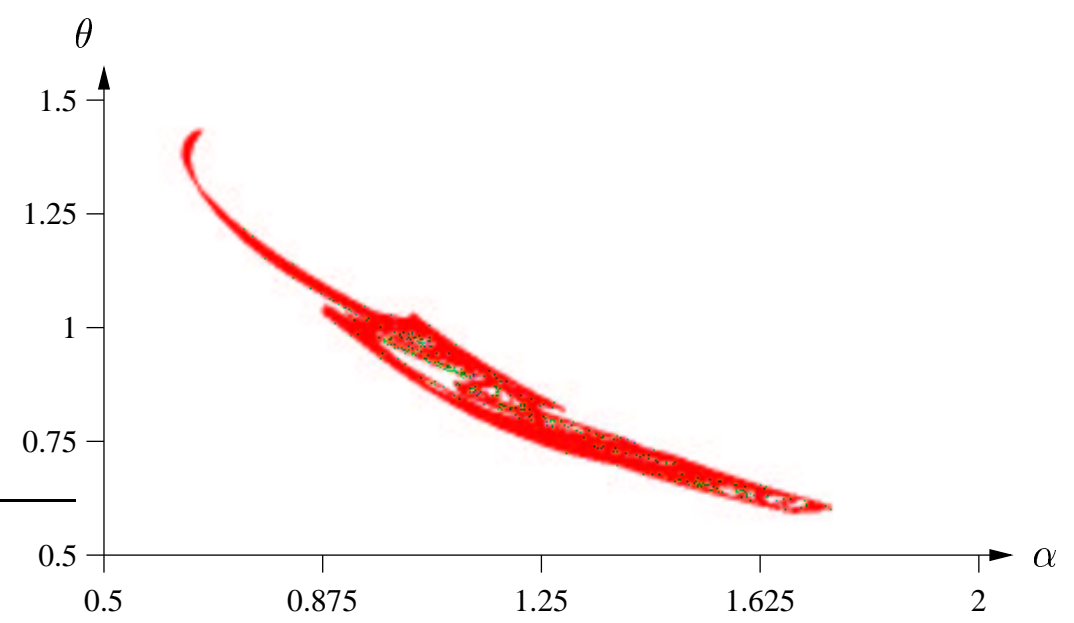

Figure 5.4: $B=0.76, \gamma=\kappa=\lambda=\mu=0.5, \mathrm{E}=0.01, \Delta=-0.05$

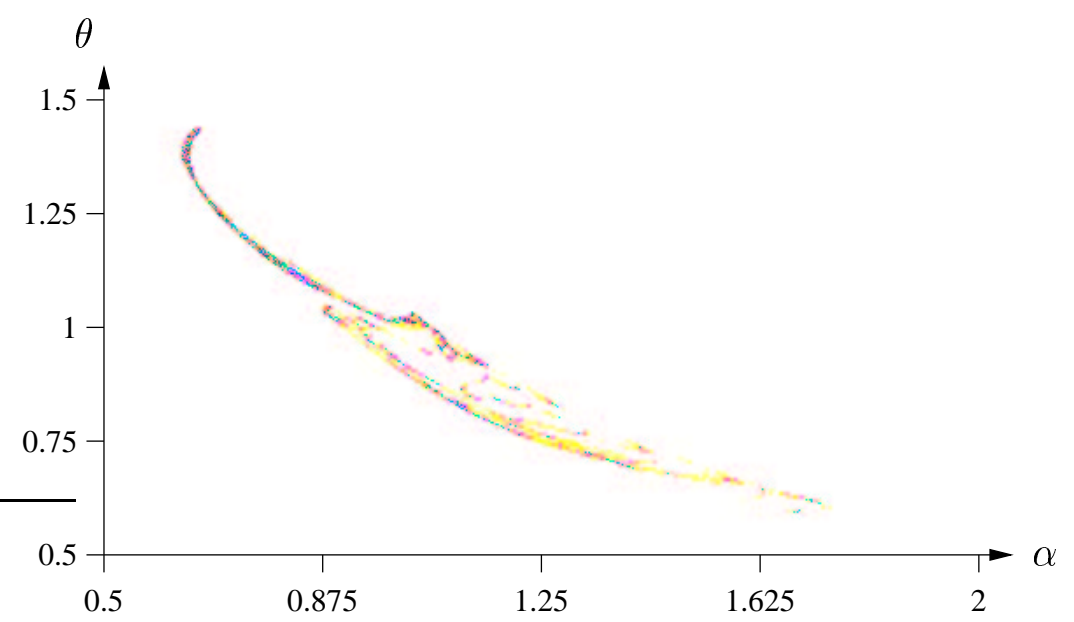

Figure 5.5: $B=0.76, \gamma=\kappa=\lambda=\mu=0.5, \mathrm{E}=0.01, \Delta=-0.05$

The almost uniform coloring in Figure 5.4 indicates that the total spread of the attractor is obtained for the last 10 percent of the $10^{6}$ iterations, while Figure 5.5 incorporates ad- 
ditional information about the densities/frequencies. The darker colors, as concentrated in the 'North-West' part of the diagram, indicate higher densities.

In fact, the calculation of the associated cumulative marginal distribution functions $F(\alpha)$ and $F(\theta)$ yield the two curves depicted in Figures 5.6 and 5.7. These indicate that the probability of positive inflation and of a wage rate less than one is greater than 0.5. Therefore, more than half of the time the economy will be in full employment with demand rationing i.e. in the repressed inflation regime $\mathbf{I}$.

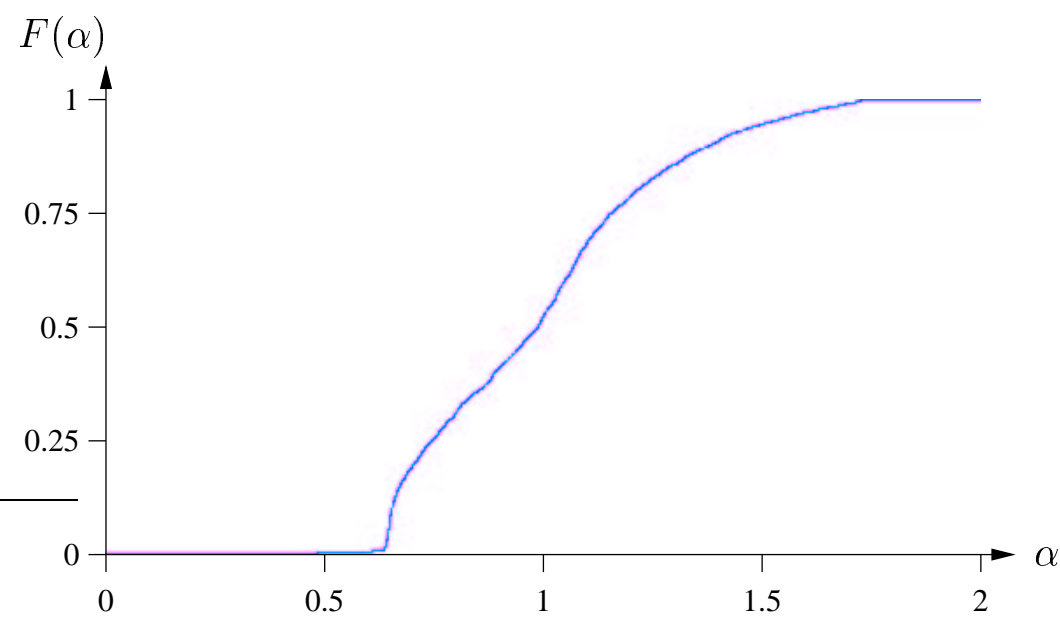

Figure 5.6: $B=0.76, \gamma=\kappa=\lambda=\mu=0.5, E=0.01, \Delta=-0.05$

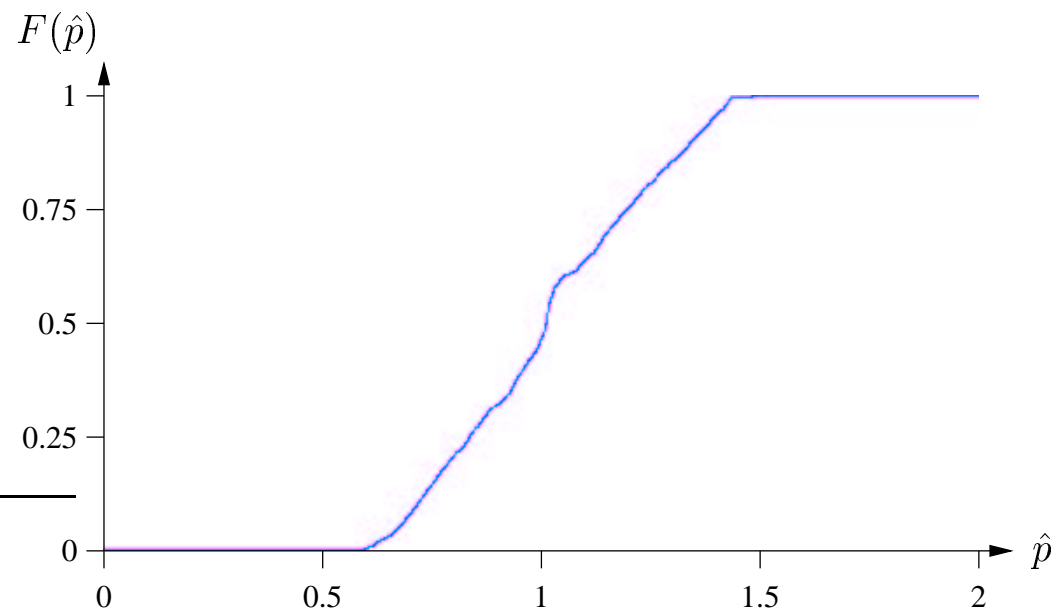

Figure 5.7: $B=0.76, \gamma=\kappa=\lambda=\mu=0.5, E=0.01, \Delta=-0.05$

To analyze the issue of volatility in more detail, let $\hat{w}_{t}:=w_{t+1} / w_{t}, \hat{p}_{t}:=p_{t+1} / p_{t}=\theta_{t+1}$, and $\hat{X}_{t}:=X_{t+1} / X_{t}$ denote the rates of change of wages, prices, and of nominal exchange rates respectively. Empirical data typically show that change of exchange rates are an order of magnitude more volatile than change of price levels. For the given values of $B=0.76, \gamma=\kappa=\lambda=\mu=0.5, \mathrm{E}=0.01, \Delta=-0.05$ the limiting behavior is described 
by a complex (non periodic) orbit with time series given in 5.8. The Figure portrays a typical time series of the rates of change showing very clearly the higher volatility of the exchange rate as compared to the domestic variables, especially the price level.

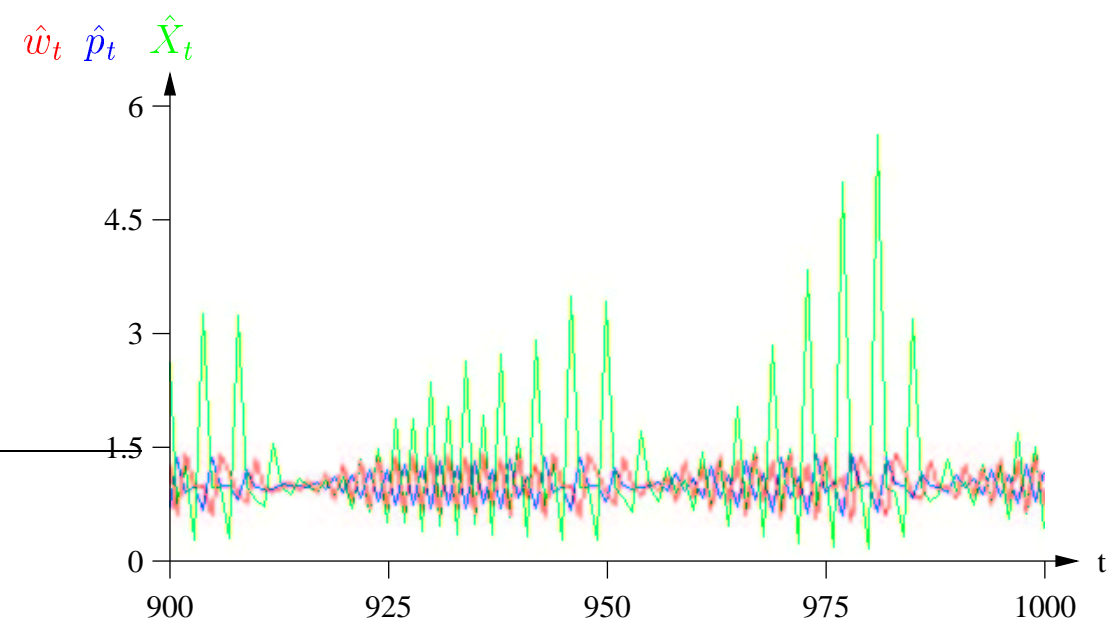

Figure 5.8: $B=0.76, \gamma=\kappa=\lambda=\mu=0.5, \mathrm{E}=0.01, \Delta=-0.05$

Figure 5.9, 5.10 and 5.11 and Table 2 supply additional evidence of the distinct volatility features in the complex case by showing a projection of the complex attractor into the $\hat{p}_{t}, \hat{X}_{t}$ state space, the marginal densities (histograms) of the exchange rate and the rate of inflation as well as a table of descriptive statistics. These reveal distinctive features: a variance of the exchange rate ten times as large as that of domestic prices and wages; a skewness of the exchange rate of more than plus one half, while the skewness of prices is only about a third of that of the exchange rate with that of wages being small and negative.

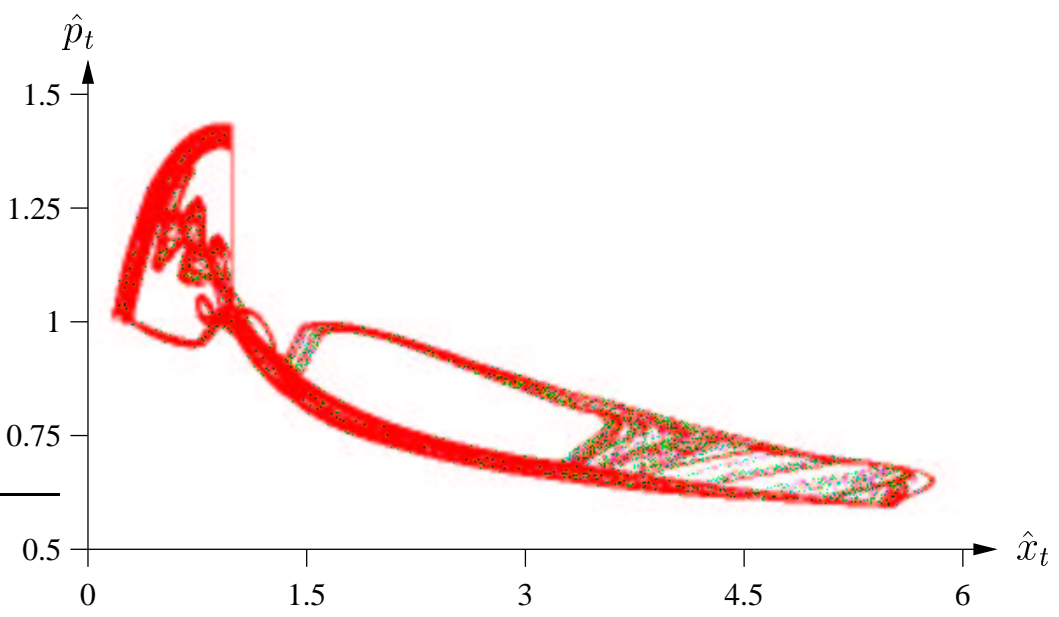

Figure 5.9: $B=0.76, \gamma=\kappa=\lambda=\mu=0.5, \mathrm{E}=0.01, \Delta=-0.05$ 


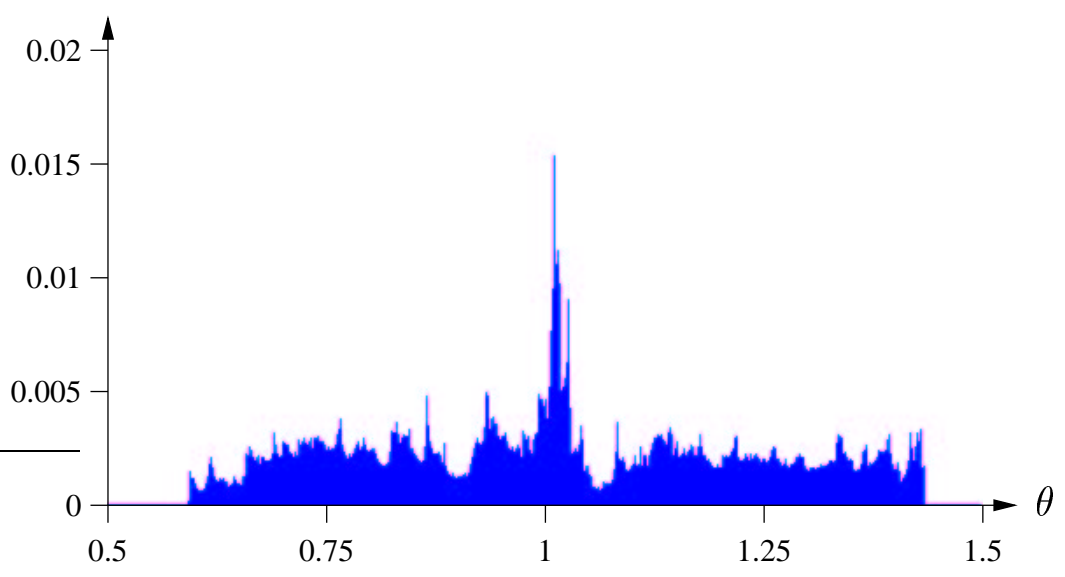

Figure 5.10: $B=0.76, \gamma=\kappa=\lambda=\mu=0.5, \mathrm{E}=0.01, \Delta=-0.05$

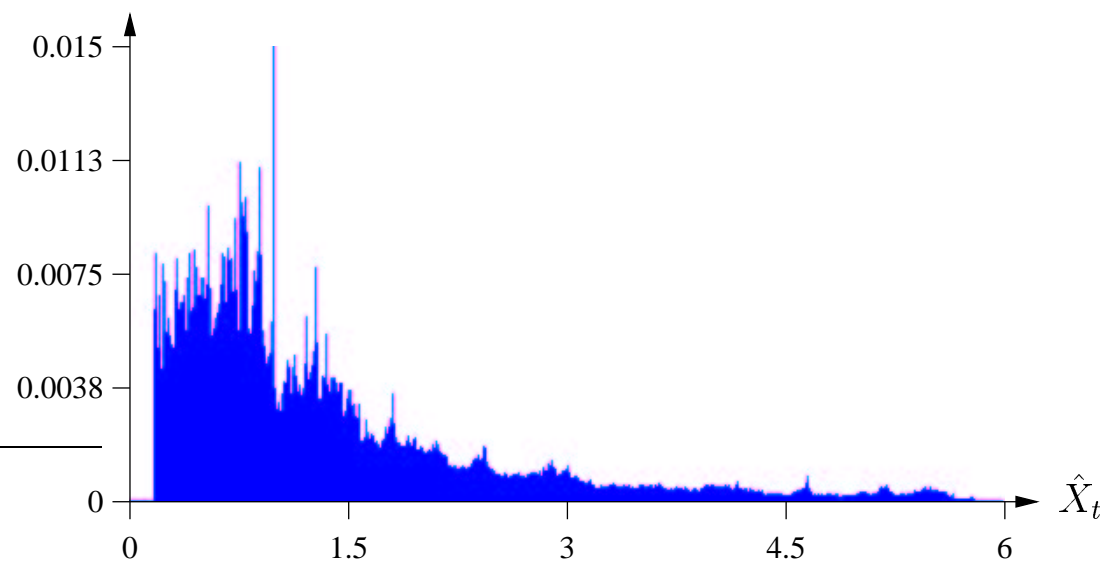

Figure 5.11: $B=0.76, \gamma=\kappa=\lambda=\mu=0.5, \mathrm{E}=0.01, \Delta=-0.05$

\begin{tabular}{|c|l|l|l|l|l|}
\hline variable & mean & variance & std. dev. & skewness & kurtosis \\
\hline$\hat{p}_{t}$ & 1.001 & 0.0219352 & 0.148105 & 0.233568 & -1.20406 \\
\hline$\hat{w}_{t}$ & 1.00826 & 0.0355421 & 0.188526 & -0.0490178 & -1.34361 \\
\hline$\hat{X}_{t}$ & 1.13768 & 0.351347 & 0.592746 & 0.613577 & -1.01278 \\
\hline
\end{tabular}

Table 2: Descriptive statistics 


\section{Periodic Cycles}

If the adjustment speeds on all markets are set to $\gamma=\kappa=\lambda=\mu=0.4$ the limiting behavior of the economy is a finite cycle of order four. Figures 5.12 and 5.13 and portray the time series of $\hat{p}_{t}, \hat{w}_{t}$, and $\hat{X}_{t}$ and a projection of the attractor into the space of $\left(\hat{X}_{t}, \hat{p}_{t}\right)$. As in the complex case one observes greater variability of the exchange rate.

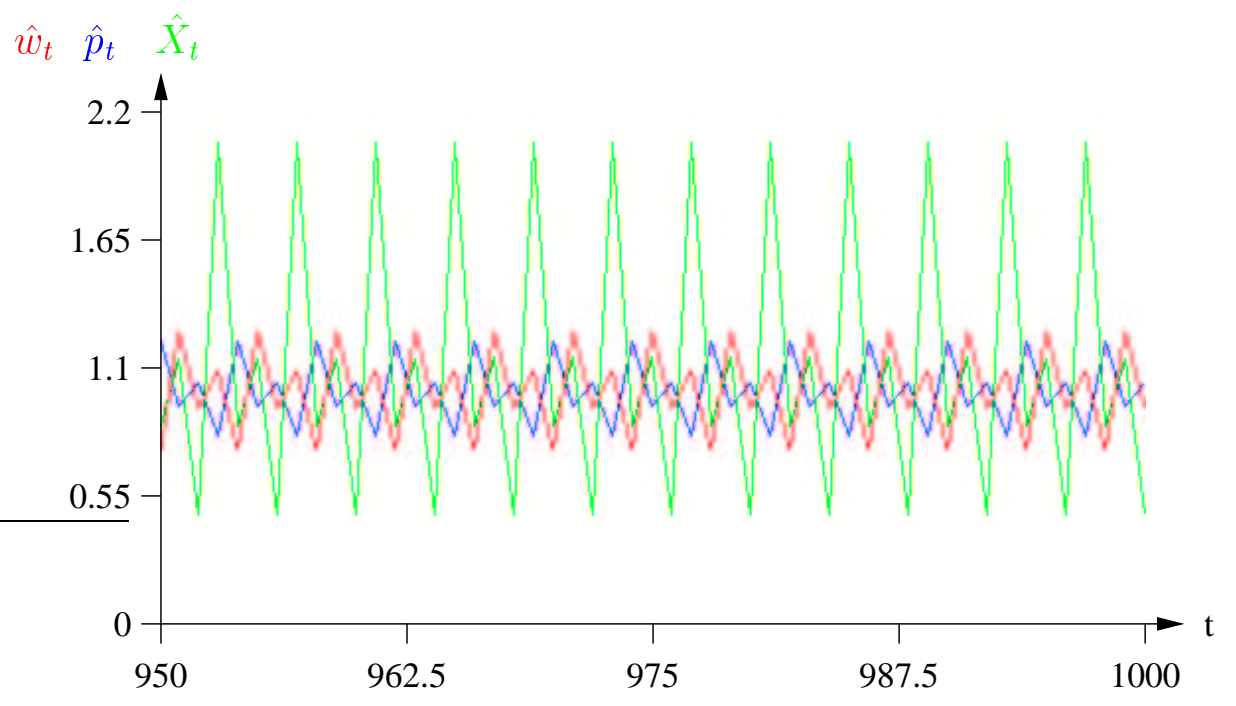

Figure 5.12: $B=0.76, \gamma=\kappa=\lambda=\mu=0.4, \mathrm{E}=0.01, \Delta=-0.05$

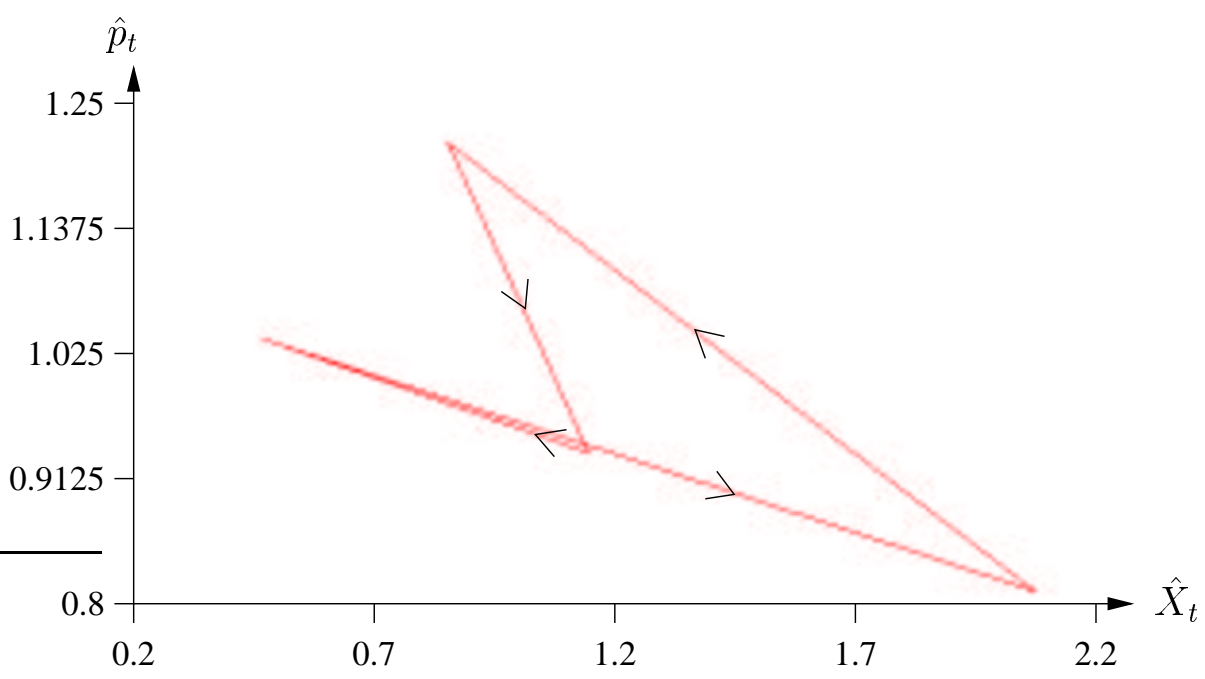

Figure 5.13: $B=0.76, \gamma=\kappa=\lambda=\mu=0.4, \mathrm{E}=0.01, \Delta=-0.05$ 


\subsection{Openness and Loss of Stability}

The analysis above considered the situation of an open economy with postive foreign demand $(E 0.01)$ and a deflationary bond policy by the domestic government $(\Delta=$ $-0.05)$. If one compares the open economy with the closed economy $(E=0)$ by means of the cyclogram below one observes a substantial loss of stability of the closed economy after opening the economy and subjecting it to the influence of an international capital market. (The cyclogram 5.2 is reproduced below for convenience.)

Closed Economy: $E=0, \Delta=-0.05$

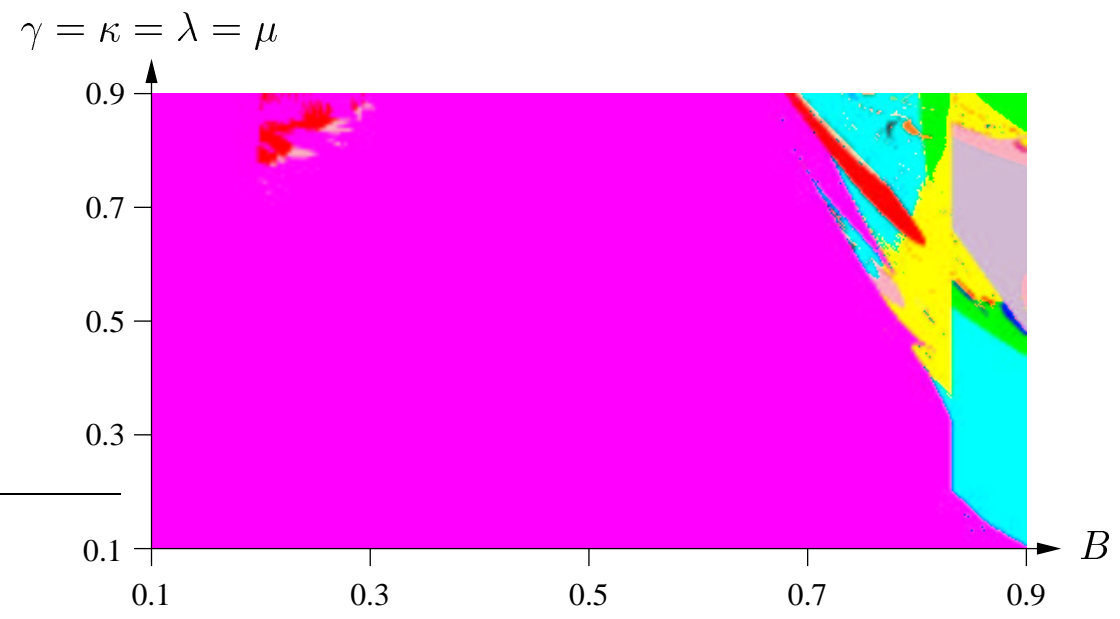

Figure 5.14: $B \in[0.1,0.9], \gamma=\kappa=\lambda=\mu \in[0.1,0.9]$

Open Economy: $E=0.01, \Delta=-0.05$

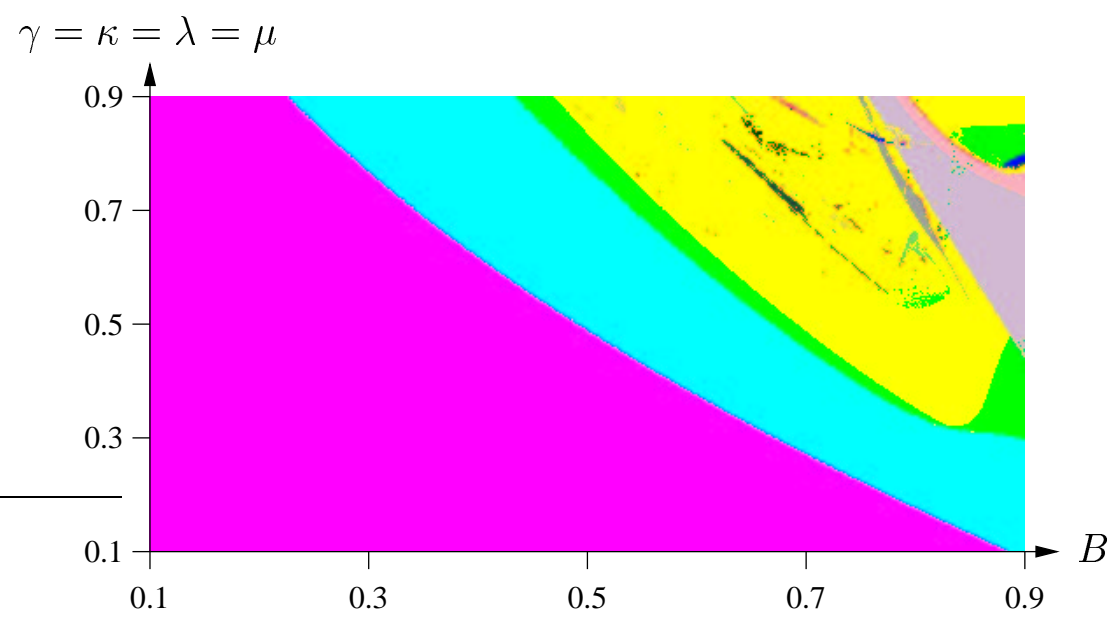

Figure 5.15: $B \in[0.1,0.9], \gamma=\kappa=\lambda=\mu \in[0.1,0.9]$ 
The numerical analysis reveals that this loss of stability is much more dramatic for $\Delta=0$ and for $\Delta=0.05$. The next set of diagrams presents pairs of cyclograms for the closed and open economy for the same value of $\Delta$ and the same range of bifurcation parameters.

Closed Economy: $E=0, \Delta=0$

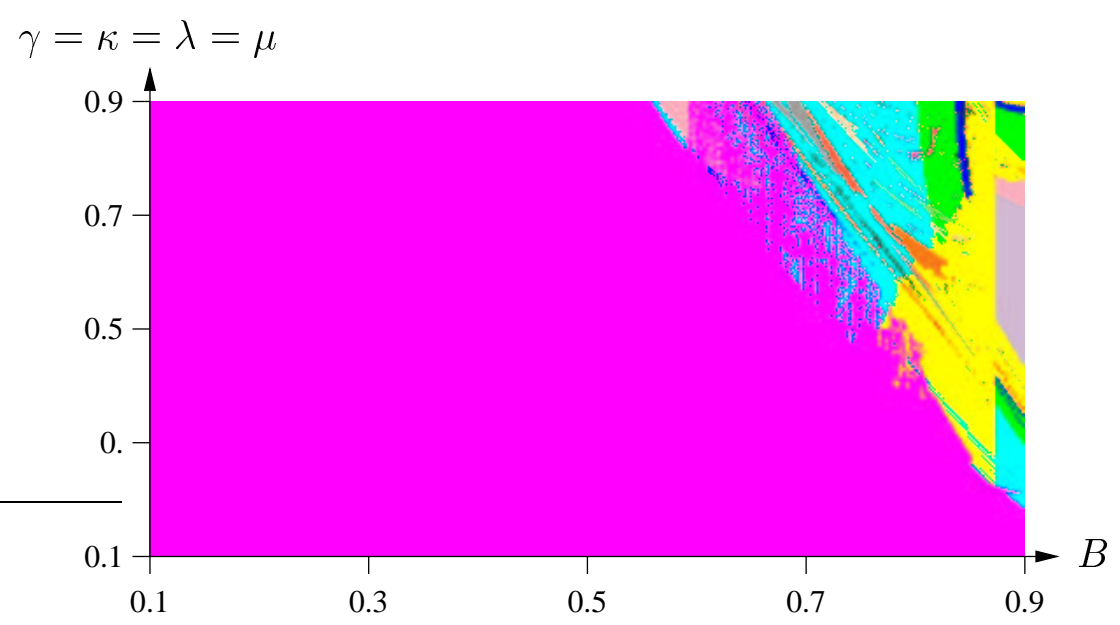

Figure 5.16: $B \in[0.1,0.9], \gamma=\kappa=\lambda=\mu \in[0.1,0.9]$

Open Economy: $E=0.01, \Delta=0$

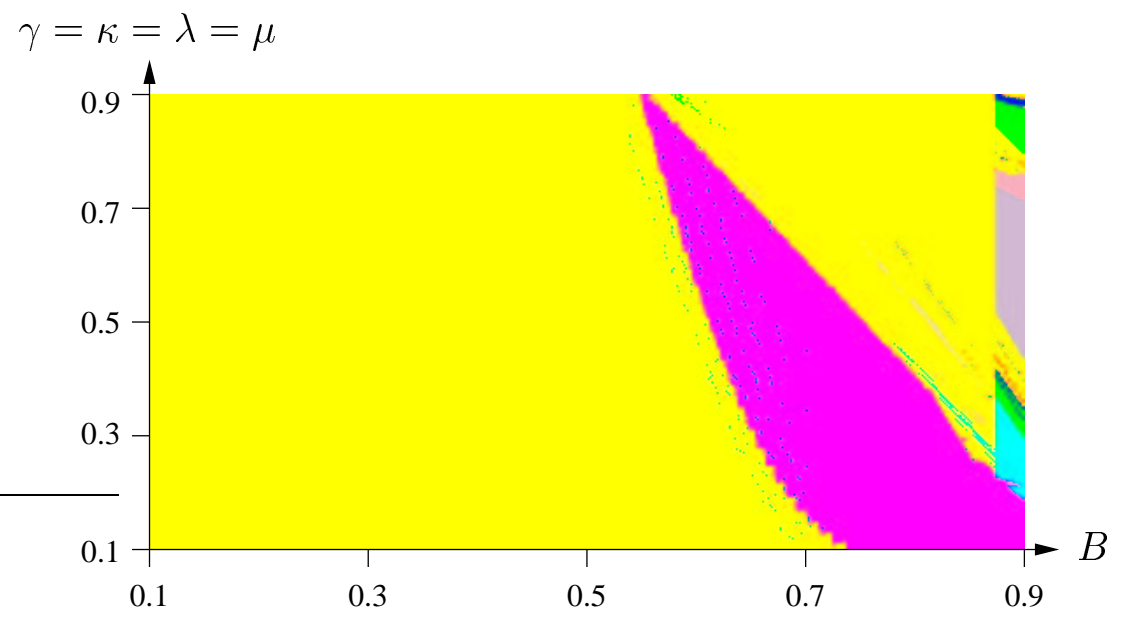

Figure 5.17: $B \in[0.1,0.9], \gamma=\kappa=\lambda=\mu \in[0.1,0.9]$ 
Closed Economy: $E=0, \Delta=0.05$

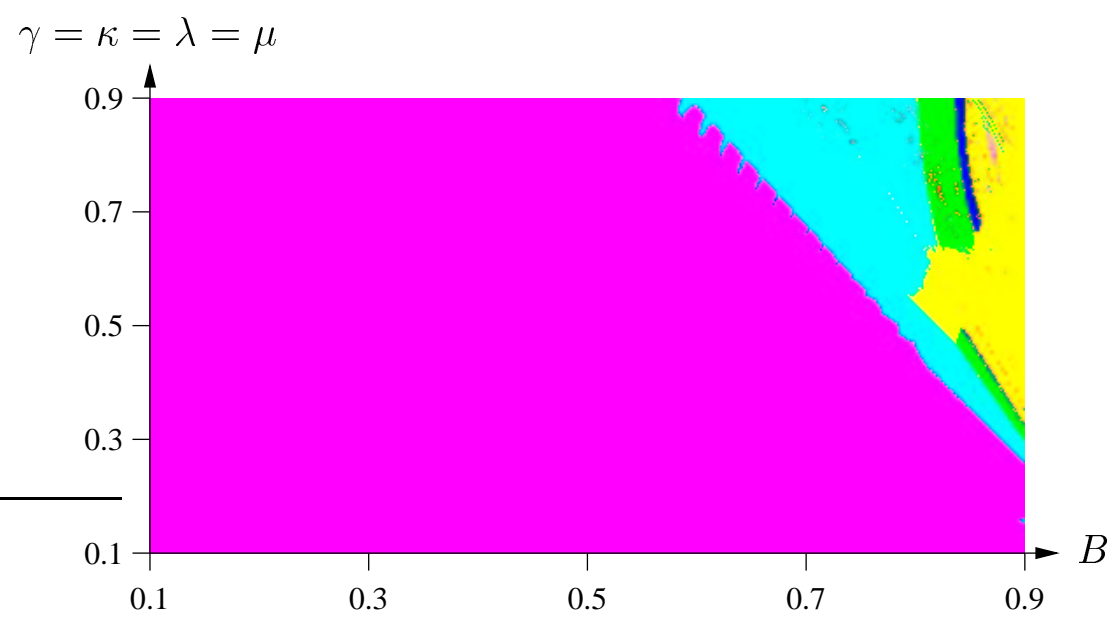

Figure 5.18: $B \in[0.1,0.9], \gamma=\kappa=\lambda=\mu \in[0.1,0.9]$

Open Economy: $E=0.01, \Delta=0.05$

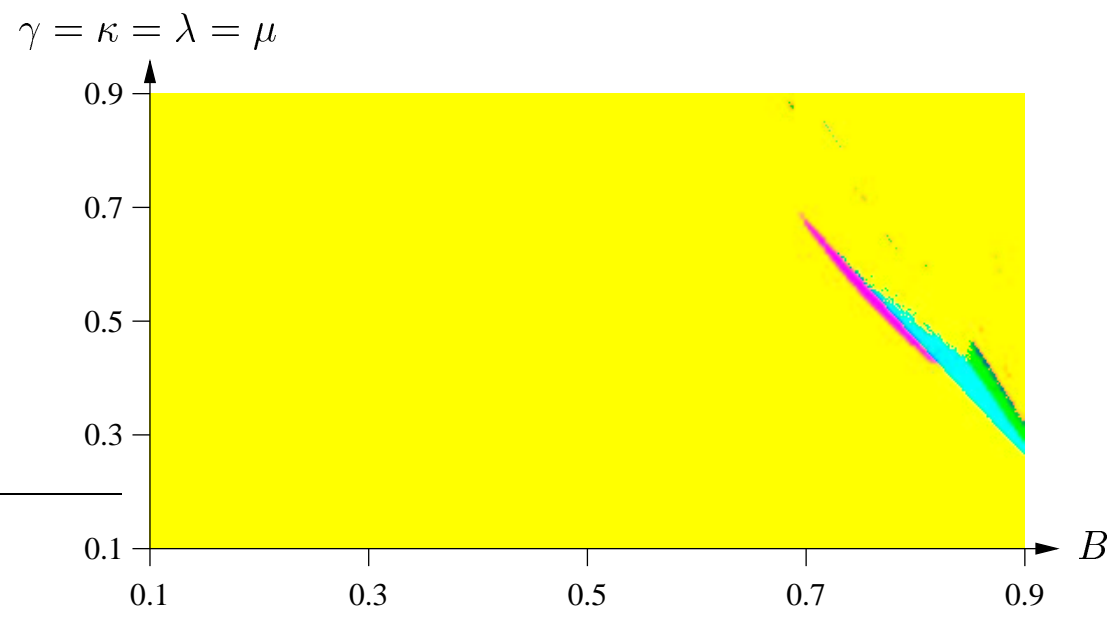

Figure 5.19: $B \in[0.1,0.9], \gamma=\kappa=\lambda=\mu \in[0.1,0.9]$

Notice that the area of cyan red which marks values of parameters with associated stable fixed points decreases successively as $\Delta$ changes from -0.05 to 0.05 . In Figur 5.19 the area of stable fixed points has disappeared almost completely with a small area of stable cycles of order two and four remaining. Clearly, a further detailed bifurcation analysis has to be carried out here. However, this numerical analysis leads to the general conclusion that within the paradigm of perfect capital markets and interest parity international capital markets may severely destabilize closed domestic economies. 


\section{Conclusions}

The results of this paper provide a first explicit account of possible dynamics of a small open economy in its relationship to perfect international capital markets under the UIP hypothesis. They show that the structural non linear relationships between asset markets and real markets may generate permanent endogenous fluctuations. These are the result of the interaction of a strong expectations feed back with sluggish domestic price and wage adjustments under fully competitive/price taking behavior in all markets. No elements of market imperfections are present. Moreover, the cyclical recurrence arises within a deterministic model, with no random perturbations being present. The numerical analysis shows examples which confirm the typical empirically observed high volatility of the nominal exchange rate compared with that of real/domestic variables. This result directs us closer toward a possible answer to one of the pricing puzzles.

The model demonstrates that the channels between domestic real markets and competitive international financial markets induce clear dynamic correlations between real and monetary phenomena whose qualitative properties depend heavily on particular structurally given values of the domestic economy as well as of the international market. It has to be taken as one of the surprising findings that the introduction of competitive international capital markets within this class of models induces strong destabilizing forces making stable regular periodic behavior impossible. With these results further research should investigate the structural relationships between domestic macroeconomic variables and international capital markets as well as its policy implications. Moreover, a more detailed analytical investigation of the stability properties of this class of dynamic models will identify more specifically the sources of the volatility and of the fluctuations. 


\section{References}

Barro, R. J. \& H. I. Grossman (1971): "A General Disequilibrium Model of Income and Employment", American Economic Review, 61, 82-93.

Benassy, J.-P. (1975): "Neo-Keynesian Disequilibrium Theory in a Monetary Economy", Review of Economic Studies, 42, 503-523.

Betts, C. \& M. B. Devereux (2000): "Exchange Rate Dynamics in a Model of Pricing-to-Market", Journal of International Economics, 50, 215-244.

Böнm, V. (1993): "Recurrence in Keynesian Macroeconomic Models", in Nonlinear Dynamics in Economics and Social Sciences, ed. by F. Gori, L. Geronazzo \& M. Galeotti. Springer-Verlag, Heidelberg a.o.

Böhm, V., M. Lohmann \& H.-W. Lorenz (1997): "Dynamic Complexity in a Keynesian Macroeconomic Model - Revised Version", Discussion Paper 288, Department of Economics, University of Bielefeld.

Böhm, V. \& J. Wenzelburger (1997): "Expectational Leads in Economic Dynamical Systems", Discussion Paper 373, Department of Economics, University of Bielefeld.

(1999): "Expectations, Forecasting and Perfect Foresight - A Dynamical Systems Approach", Macroeconomic Dynamics, 3(2), 167-186.

Chari, V., P. Kehoe \& E. McGrattan (2000): "Can Sticky Price Models Generate Volatile and Persistent Real Exchange Rates?", NBER Working Paper 7869, National Bureau of Economic Research, Cambridge (Mass.).

Dornbusch, R. (1976): "Expectations and Exchange Rate Dynamics", Journal of Political Economy, 84(6), 1161-1176.

KAAs, L. (1995): "Steady States and Local Bifurcations in a Dynamic Disequilibrium Model", Discussion Paper 300, Department of Economics, University of Bielefeld.

Kollmann, R. (2001): "The Exchange Rate in a Dynamic-Optimizing Business Cycle Model with Nominal Rigidities: A Quantitative Investigation", Journal of International Economics, 55, 243-262.

Lane, P. R. (2001): "The New Open Economy Macroeconomics: A Survey", Journal of International Economics, 54, 235-266.

Malinvaud, E. (1977): The Theory of Unemployment Reconsidered. Blackwell Publishers, Oxford a.o.

Mundell, R. (1968): International Economics. MacMillian, New York a.o. 
NeARY, J. P. (1990): "Neo-Keynesian Macroeconomics in an Open Economy", in Advanced Lectures in Quantitative Economics, ed. by F. van der Ploeg. Academic Press, New York a.o.

Obstfeld, M. \& K. Rogoff (1995): "Exchange Rate Dynamics Redux", Journal of Political Economy, 103, 624-660.

(2001): "The Six Major Puzzles in International Macroeconomics: Is There a Common Cause?", in NBER Macroeconomics Annual 2000, ed. by B. S. Bernanke \& K. Rogoff. The MIT Press.

Rogoff, K. (1996): "The purchasing Power Parity Puzzle", Journal of Economic Literature, 34, 647-668.

(1998): "Perspectives on Exchange Rate Volatility", in International Capital Flows, ed. by M. Feldstein. NBER and University of Chicago Press, Chicago.

Svensson, L. E. O. \& S. Wijnbergen (1989): "Nontraded Assets in Incomplete Markets: Pricing and Portfolio Choice", Economic Journal, 99, 785-805. 